\title{
Terapia fotodinâmica como adjuvante no tratamento da doença periodontal em equinos
}

[Adjunctive photodynamic therapy as a treatment for periodontal disease in equines]

\author{
L.L.R. Dias $^{1}$, J.C. Guerreiro ${ }^{2}$, J.C. Gandini ${ }^{3}$, K. Grolli ${ }^{4}$, M.L. Bruschi ${ }^{5}$, M.G. Ribeiro ${ }^{2}$ \\ ${ }^{1}$ Universidade Sociedade Educacional de Santa Catarina - Itajaí, SC \\ ${ }^{2}$ Universidade Estadual de Maringá - Umuarama, PR \\ ${ }^{3}$ Aluno de pós-graduação - Universidade Estadual de Maringá - Umuarama, PR \\ ${ }^{4}$ Médica veterinária autônoma - Três Passos, RS \\ ${ }^{5}$ Universidade Estadual de Maringá - Maringá, PR
}

\begin{abstract}
RESUMO
A doença periodontal é uma afecção comum, relacionada ao aprisionamento de alimentos em diastemas não fisiológicos, em equinos. $\mathrm{O}$ tratamento consiste na correção da causa primária, limpeza e desbridamento do sulco gengival, denominado tratamento convencional (TC). Frequentemente antimicrobianos são necessários, pela gravidade ou patogenicidade dos agentes. A terapia fotodinâmica adjuvante (TF) tem sido estudada pelo seu potencial combate bacteriano, sem causar resistência bacteriana. O objetivo deste estudo foi analisar o uso da TF na doença periodontal, experimentalmente induzida, em dentes incisivos de equinos, e compará-la com o TC. O TC não resultou em melhora clínica estatisticamente, tanto em graus como em profundidade, apenas numérica na profundidade aos 30 dias. A TF foi empregada em dentes com profundidade maior da bolsa periodontal que a do grupo TC e, mesmo assim, apresentou melhora clínica já com sete dias, e mais efetiva aos 30, atingindo, em média, o valor considerado normal, três milímetros. A TF apresentou potencial para ser aplicada na rotina, pelo incremento nos resultados, sem causar efeitos colaterais.
\end{abstract}

Palavras-chave: cavalo, cirurgia, odontologia, periodontite, periodontologia

\begin{abstract}
Periodontal disease is a common condition, related to the entrapment of food in non-physiological diastemas in horses. Treatment consists of correction of the primary cause, cleansing and debridement of the gingival sulcus, called Conventional Therapy $(C T)$. Often antimicrobials are requested due to the severity or pathogenicity of the agents. Adjuvant Photodynamic Therapy (PDT), has been studied for its potential bacterial combat, without causing bacterial resistance. The objective of this study was to analyze the use PDT with the experimentally induced periodontal disease in the incisor teeth of horses, and to compare with the CT. The CT did not result in clinical improvement, either in degrees or millimeters. The PDT was used in teeth with a greater depth of the periodontal pocket than the TC group, and even then, showed clinical improvement in only seven days, and more effective at 30, reaching the three millimeter value considered normal on average. The PDT presented the potential to be applied in the routine by the increase in the results without causing side effects.
\end{abstract}

Keywords: dentistry, horse, periodontitis, periodontology, surgery

\section{INTRODUÇÃO}

A doença periodontal é uma afecção dolorosa, comum em equinos (Casey, 2013), causada principalmente pelo acúmulo de alimento no sulco crevicular (Klugh, 2005; Casey, 2013;
Rawlinson e Earley, 2013; Tremaine, 2013; Kennedy e Dixon, 2018). Alimentos encarcerados no espaço interdental propiciam a colonização de bactérias periodontopatogênicas. Elas liberam enzimas e toxinas que danificam o periodonto, consequentemente ativam a resposta inflamatória

Recebido em 10 de maio de 2019

Aceito em 6 de abril de 2020

E-mail: 1.lopesrinodias@gmail.com 
por meio de mediadores, os quais causam o agravo, formando as bolsas periodontais (Klugh, 2005; Casey, 2013; Rawlinson e Earley, 2013; Tremaine, 2013; Kennedy e Dixon, 2018). Dependendo da severidade, ocorre a destruição do periodonto de proteção, exposição das demais estruturas, levando à osteomielite, lesão endodôntica, apical, e/ou perda dentária (Casey, 2013; Rawlinson e Earley, 2013).

O tratamento convencional (TC) da periodontite consiste na correção da causa primária, limpeza e desbridamento do sulco crevicular (Klugh 2005; Casey, 2013; Tremaine, 2013). Com certa frequência, terapia antimicrobiana é necessária, seja pela gravidade da lesão, seja pela patogenicidade dos agentes (Klugh, 2005; Rawlinson e Earley, 2013; Tremaine, 2013). O problema dos antibióticos, além dos efeitos adversos (Tremaine, 2013), é a resistência bacteriana, questão importantíssima na saúde humana e animal.

Segundo Alwaeli et al. (2015), Jervøe-Storm et al. (2015), Moreira et al. (2015), Queiroz et al. (2015), Carrera et al. (2016), Pulikkotil et al. (2016), Vohra et al. (2016) e Belinello-Souza et al. (2017), a terapia fotodinâmica (TF) tem sido proposta como adjuvante no tratamento da doença periodontal pelo efeito antimicrobiano, com a vantagem de não causar resistência bacteriana (Jervøe-Storm et al., 2015; Vohra et al., 2016), mas sem estudos publicados desse emprego, em equinos.

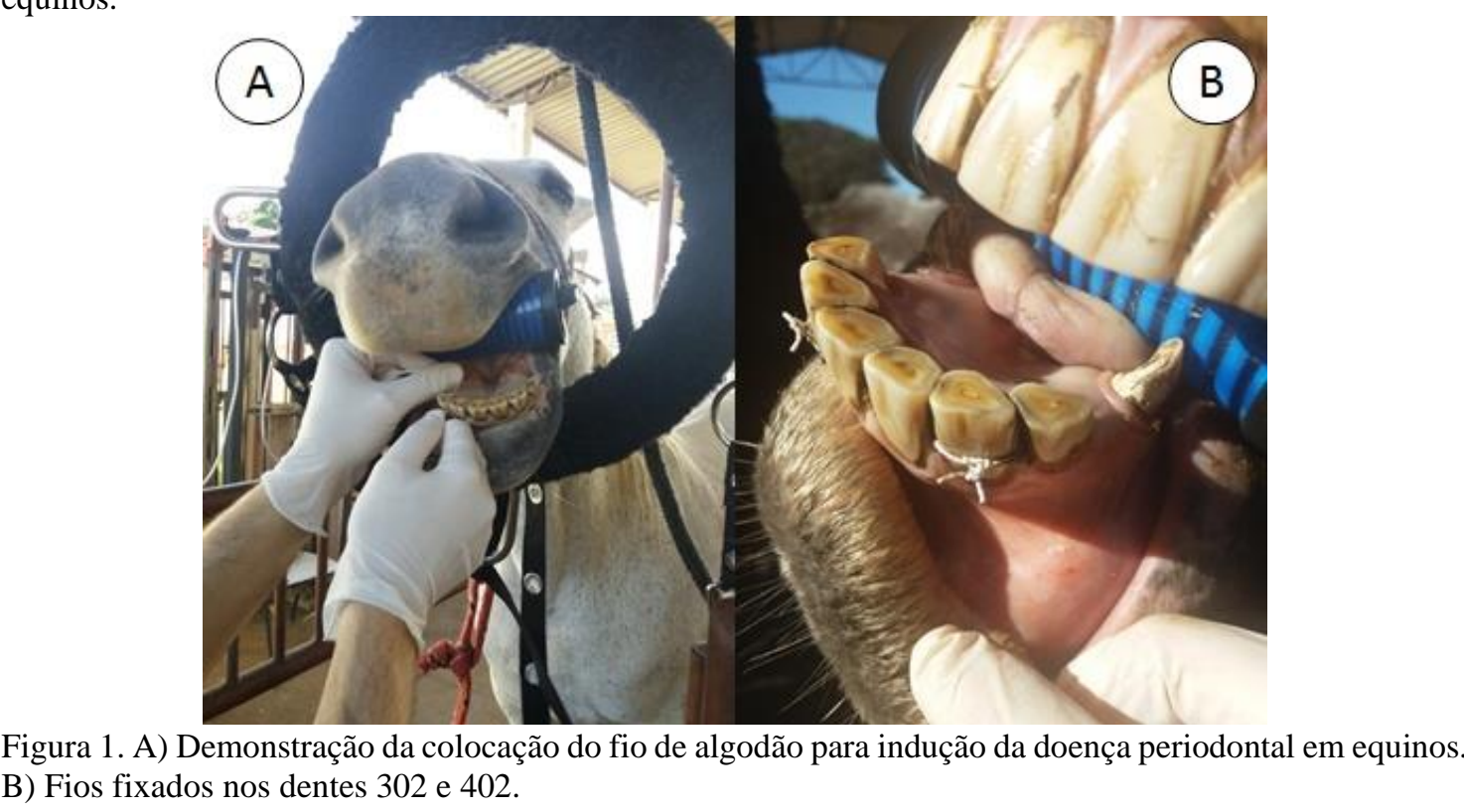

Figura 1. A) Demonstração da colocação do fio de algodão para indução da doença periodontal em equinos. B) Fios fixados nos dentes 302 e 402.
A TF consiste na excitação de um corante, por uma fonte de luz, que, na exposição do oxigênio, gera espécies reativas de oxigênio e oxigênio de singleto, os quais são tóxicos para bactérias e tecido danificado (Alwaeli et al., 2015; Campanile et al., 2015; Jervøe-Storm et al., 2015; Moreira et al., 2015; Queiroz et al., 2015; Carrera et al., 2016; Junqueira et al., 2016; Pulikkotil et al., 2016; Vohra et al., 2016; Belinello-Souza et al., 2017; Ervolino et al., 2019).O objetivo deste trabalho foi estudar o uso da $\mathrm{TF}$ na doença periodontal experimental e compará-la à TC, em equinos.

\section{MATERIAL E MÉTODOS}

Esta pesquisa foi aprovada pela Comissão de Ética no Uso de Animais (Ceua), da Universidade Estadual de Maringá (UEM), sob o número de protocolo 3869270818. A indução da periodontite foi inspirada nos estudos de Belinello-Souza et al. (2017) e Ervolino et al. (2019) em ratos, com adaptações para a espécie equina, sendo empregada em 18 gengivas saudáveis, duas por animal, de nove equinos adultos, sem raça definida. Consistiu na colocação de um fio de algodão (Corrente Cordonê, 00, Algodão, Coats Corrente, Brasil), nos espaços interdentais, esquerdo e direito do respectivo dente, de forma a envolvê-lo (Fig. 1). Esse fio foi fixado com nós de cirurgião e mantido por 30 dias, com observações diárias, para a recolocação, caso fosse necessária. 
Os animais selecionados para indução não receberam tratamentos odontológicos e/ou com antibióticos, 90 dias prévios ao estudo, e estavam em boa condição de saúde, constatada por exame clínico e hemograma. Os dentes escolhidos para indução da lesão foram incisivos permanentes, 302 e 402 ou 303 e 403, que estivessem entre dois permanentes, saudáveis - confirmados com avaliação clínica e radiográfica.

Antes da indução da doença periodontal, esses animais foram distribuídos em dois grupos: o tratamento convencional (TC), que consistiu na limpeza e no desbridamento da bolsa periodontal, com quatro animais, e o tratamento convencional associado à terapia fotodinâmica (TF), com cinco animais. Previamente aos procedimentos de avaliação periodontal, à indução das lesões, à limpeza e curetagem periodontal, a boca foi enxaguada, o animal sedado com cloridrato de xilazina a $10 \%(0,5-1,5 \mathrm{mg} / \mathrm{kg}$, intravenosa), a cabeça suspensa com uma cabeçada odontológica (Horse Dental Care, Brasil), e a boca aberta com um espéculo odontológico para incisivos (Horse Dental Care, Brasil).

Findado o período de indução, os periodontos foram selecionados para o início dos tratamentos no dia zero. O fio e os alimentos compactados foram removidos, o periodonto enxaguado com água, e o aspecto gengival observado (Klugh, 2005; Casey, 2013; Rawlinson e Earley, 2013). A profundidade do sulco gengival e a presença da afecção - superior a três milímetros (Griffin, 2013) foram determinadas com uma sonda periodontal milimetrada (146-P, Millenium,
Brasil), inserida perpendicularmente no sulco periodontal. Também se empregou uma classificação adaptada de Klugh (2005), Tab. 1, a qual associou a avaliação clínica à radiográfica (Fig. 2), em uma escala de zero a quatro, a fim de selecionar os graus dois e três para o estudo clínico. Por meio desses critérios, todas as 18 afecções periodontais induzidas foram consideradas aptas para o estudo. A profundidade e a classificação das bolsas periodontais também foram utilizadas para acompanhar a evolução dos tratamentos nos dias sete e 30 .

Em seguida à avaliação, empregou-se o tratamento convencional nos periodontos selecionados. Foram enxaguados com água e secos com compressas de gazes (Algodão, Dental Cremer, Brasil). Depois, toda a bolsa foi curetada, com uma cureta periodontal (MC CALL, 17-18, Millenium, Brasil). Tal procedimento foi empregado nos dois grupos, no dia zero. $\mathrm{Na}$ sequência, apenas para o grupo TF, empregou-se a terapia fotodinâmica.

Para a TF, o agente fotossenbilizador utilizado foi o azul de metileno, na forma de sol-gel (Azul de Metileno 0,5\%, P407 17,5\%, C934P 0,2\%), descrito por Junqueira et al. (2016), mantido em frasco de vidro âmbar, refrigerado a $5^{\circ} \mathrm{C}$. Foi aplicado $0,6 \mathrm{~mL}$ com uma seringa, por todo o periodonto. Após a aplicação, houve a espera de um minuto, para incidir diodo emissor de luz ( $L E D \mathrm{~s}$ ), que possui $650 \mathrm{~nm}$ de comprimento de onda. A fonte de luz foi posicionada a 10 centímetros de distância, com sete aplicações, por 10 minutos, intercaladas com 48 horas.

Tabela 1. Classificação da doença periodontal em equinos, adaptada de Klugh (2005)

\begin{tabular}{|c|c|c|c|c|c|}
\hline Classificação & Gengiva & Cemento & Mobilidade & Radiografia & $\begin{array}{l}\text { Envolvimento } \\
\text { osso alveolar }\end{array}$ \\
\hline Grau 0 & Normal & Normal & 0 & Normal & $0 \%$ \\
\hline Grau 1 & $\begin{array}{l}\text { Inchada, } \\
\text { avermelhada, } \\
\text { sensível }\end{array}$ & $\begin{array}{l}\text { Normal ou } \\
\text { supragengival }\end{array}$ & 0 & Normal & $0 \%$ \\
\hline Grau 2 & $\begin{array}{l}\text { Compactação, } \\
\text { inflamada ou } \\
\text { necrótica }\end{array}$ & $\begin{array}{l}\text { Supra e } \\
\text { subgengival }\end{array}$ & 0 ou 1 & $\begin{array}{l}\text { Define o } \\
\text { envolvimento }\end{array}$ & $<25 \%$ \\
\hline Grau 3 & $\begin{array}{l}\text { Compactação, } \\
\text { inflamada ou } \\
\text { necrótica }\end{array}$ & $\begin{array}{l}\text { Supra e } \\
\text { subgengival }\end{array}$ & 1 ou 2 & $\begin{array}{l}\text { Perda óssea, } \\
\text { alterações apicais e } \\
\text { coroa reserva }\end{array}$ & $<50 \%$ \\
\hline Grau 4 & $\begin{array}{l}\text { Edema, } \\
\text { ulceração, } \\
\text { necrose e pus }\end{array}$ & $\begin{array}{l}\text { Supra e } \\
\text { subgengival }\end{array}$ & 2 ou 3 & $\begin{array}{l}\text { Perda óssea, } \\
\text { alterações apicais e } \\
\text { coroa reserva }\end{array}$ & $>50 \%$ \\
\hline
\end{tabular}




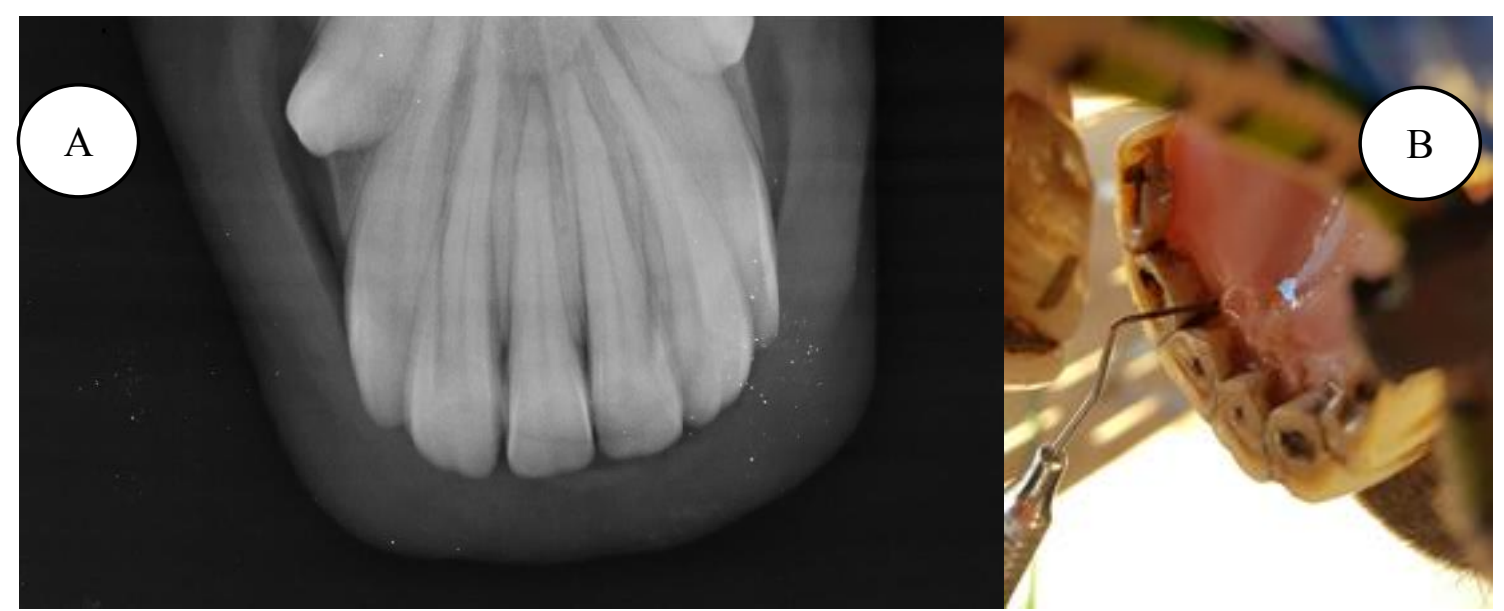

Figura 2. Avaliação radiográfica e clínica para a classificação da doença periodontal em equinos. A) Imagem radiográfica dos dentes incisivos; B) avaliação clínica comprovando doença periodontal no dente 402.

Para avaliar o efeito do tratamento, os resultados das profundidades $(\mathrm{mm})$ foram analisados em esquema fatorial, com dois fatores, sendo o primeiro os resultados dos tratamentos, com dois níveis (TC e TF), e o segundo os dias, com três níveis (zero, sete e 30). Para empregar esse esquema, duas bolsas periodontais foram removidas do grupo TF, a saber: fotodinâmica 1a e 5a. Para analisar a aplicabilidade da TF na rotina veterinária, as questões referentes à técnica foram submetidas à análise das forças, oportunidades, fraquezas e ameaças (FOFA).

Os resultados das profundidades gengivais de cada grupo, em função do tempo, foram submetidos à análise de regressão polinomial, com ajuste do modelo linear para o tratamento que utilizou a terapia fotodinâmica. Já para o tratamento convencional, não se obteve ajuste significativo. Além disso, a análise da variância das profundidades foi empregada com o teste $\mathrm{F}$, a fim de se constatarem interferências entre os fatores, sendo os desdobramentos dessas interações avaliados pelas comparações das médias, pelo teste $\mathrm{t}$ de Student com nível de significância de 5\%. Esses dados foram avaliados pelo software AgroEstat - Sistema para Análises Estatísticas de Ensaios Agronômicos.

\section{RESULTADOS E DISCUSSÃO}

Todas as 18 afecções periodontais, experimentalmente induzidas, foram consideradas aptas para o estudo, por terem o grau pretendido (dois), Tab. 2. As lesões com o mesmo grau garantiram a consistência dos resultados dos tratamentos, uma vez que o efeito e o protocolo são diferentes para gengivite (grau um), ou doença severa (grau quatro), comparados aos empregados nos graus dois e três.

A verificação da profundidade do sulco crevicular (Fig. 2), a princípio, determinou a presença da afecção nos sulcos maiores que três milímetros, conforme Griffin (2013). O exame radiográfico foi fundamental para classificá-la, pois permitiu averiguar a proporção de periodonto envolvido, ao correlacionar a profundidade da bolsa periodontal ao tamanho da coroa reserva, bem como o envolvimento ósseo e possíveis lesões em estruturas adjacentes, corroborando com Klugh (2005) e Griffin (2013).

Para um acompanhamento mais sensível do que a escala de classificação zero a quatro, a qual não permite acompanhar tendências e pequenas evoluções, foram constatadas as profundidades, em milímetros. A capacidade de observar a evolução com maior precisão foi confirmada pelas Tab. 3, 4 e 5, pois, no dia zero, todos os periodontos apresentaram a mesma classificação (grau dois, Tab. 2), mas houve diferença estatística nas profundidades em milímetros, entre os grupos. O uso associado da profundidade em milímetros com a classificação melhora a precisão no acompanhamento da evolução da doença, sem descaracterizar a escala. 
Terapia fotodinâmica...

Tabela 2. Avaliações dos periodontos pela profundidade e pelo grau da doença periodontal, nos grupos de tratamento - convencional e fotodinâmico, durante os 30 dias de estudo

\begin{tabular}{|c|c|c|c|}
\hline Periodonto & Dia 0 & Dia 7 & Dia 30 \\
\hline Convencional $1^{\mathrm{a}}$ & 6 (grau 2) & 5 (grau 2) & 5 (grau 2) \\
\hline Convencional $1 \mathrm{~b}$ & 7 (grau 2) & 6 (grau 2) & 6 (grau 2) \\
\hline Convencional $2^{a}$ & $5($ grau 2) & 5 (grau 2) & $6($ grau 2) \\
\hline Convencional $2 b$ & $5($ grau 2) & 5 (grau 2) & 7 (grau 2) \\
\hline Convencional $3^{a}$ & 6 (grau 2) & 6 (grau 2) & $4,5(\operatorname{grau} 2)$ \\
\hline Convencional $3 \mathrm{~b}$ & 7 (grau 2) & 6 (grau 2) & 4,5 (grau 2) \\
\hline Convencional $4^{\mathrm{a}}$ & $6($ grau 2) & 8 (grau 2) & $6($ grau 2) \\
\hline Convencional $4 \mathrm{~b}$ & $6($ grau 2) & 8 (grau 2) & $6($ grau 2) \\
\hline Fotodinâmica $1^{\mathrm{a}}$ & $8($ grau 2$)$ & 7 (grau 2) & $5($ grau 2$)$ \\
\hline Fotodinâmica 1b & $8($ grau 2) & 8 (grau 2) & $4($ grau 2) \\
\hline Fotodinâmica $2^{\mathrm{a}}$ & 8 (grau 2) & 8 (grau 2) & 4 (grau 2) \\
\hline Fotodinâmica 2b & $9,5(\operatorname{grau} 2)$ & 7 (grau 2) & $3($ grau 0$)$ \\
\hline Fotodinâmica $3^{\mathrm{a}}$ & 9,5 (grau 2) & 8 (grau 2) & $4($ grau 2$)$ \\
\hline Fotodinâmica 3b & 8,5 (grau 2) & 8 (grau 2) & $3($ grau 0$)$ \\
\hline Fotodinâmica 4a & 8 (grau 2) & 4,5 (grau 2) & $0($ grau 0$)$ \\
\hline Fotodinâmica 4b & 9,5 (grau 2) & $6($ grau 2$)$ & 3 (grau 0) \\
\hline Fotodinâmica 5a & 6 (grau 2) & $3($ grau 0$)$ & $3($ grau 0$)$ \\
\hline Fotodinâmica 5b & $6($ grau 2$)$ & 4 (grau 2) & $3($ grau 0$)$ \\
\hline
\end{tabular}

Tabela 3. Análise descritiva referente à evolução dos tratamentos, tratamento convencional (TC) e terapia fotodinâmica (TF), dos periodontos estudados em equinos, durante 30 dias

\begin{tabular}{lccccc} 
Tratamento & Dia & Média & Variância & Desvio-padrão & $\begin{array}{c}\text { Erro-padrão } \\
\text { médio }\end{array}$ \\
\hline TC & 0 & 6,0000 & 0,5714 & 0,7559 & 0,2672 \\
TC & 7 & 6,1250 & 1,5535 & 1,2464 & 0,4406 \\
TC & 30 & 5,6250 & 0,7678 & 0,8762 & 0,3098 \\
TF & 0 & 8,3750 & 1,4107 & 1,1877 & 0,4199 \\
TF & 7 & 6,6875 & 2,7812 & 1,6677 & 0,5896 \\
TF & 30 & 3,0000 & 1,7142 & 1,3093 & 0,4629 \\
\hline
\end{tabular}

Tratamentos - TC: convencional; TF: terapia fotodinâmica.

Tabela 4. Análise das variâncias (teste F) das profundidades das bolsas periodontais experimentalmente induzidas em equinos, pelas interações entre os tratamentos (convencional - TC e terapia fotodinâmica TF), em relação aos dias analisados (zero, sete e 30)

\begin{tabular}{|c|c|c|c|c|}
\hline Fontes de variação & GL & & Quadrado médio & \\
\hline Efeito TC+TF & 1 & & $0,1302^{\mathrm{NS}}$ & \\
\hline Efeito Dia & 2 & & $35,3593^{* *}$ & \\
\hline Interação (TC+TF x Dia) & 2 & & $25,6302^{* *}$ & \\
\hline $\mathrm{TC}+\mathrm{TF}$ & 1 & $\begin{array}{c}\text { Dia 0 } \\
22,5625^{\text {** }}\end{array}$ & $\begin{array}{c}\text { Dia } 7 \\
1,265625^{\mathrm{NS}}\end{array}$ & $\begin{array}{c}\text { Dia } 30 \\
27,5625^{* *}\end{array}$ \\
\hline $\begin{array}{l}\text { Interação (Dia x TC) } \\
\text { Interação (Dia x TF) }\end{array}$ & $\begin{array}{l}2 \\
2\end{array}$ & & $\begin{array}{l}0,5416^{\mathrm{NS}} \\
60,4479^{* *}\end{array}$ & \\
\hline
\end{tabular}

Coeficiente de variação 20,2889

Graus de liberdade (GL); tratamento convencional (TC); terapia fotodinâmica (TF). Não significativo (NS); $* *-\mathrm{P}<0,05$. 
Tabela 5. Análise das médias (t de Student) das profundidades $(\mathrm{mm})$ das bolsas periodontais em equinos, como desdobramento das interações detectadas pelo teste F, nos tratamentos (convencional - TC e terapia fotodinâmica - TF) e nos dias analisados (zero, sete e 30)

\begin{tabular}{lcccc}
\multicolumn{1}{c}{ Dias } & 0 & 7 & 30 & Média total \\
\hline Média TC & $6,0000 \mathrm{Ba}$ & $6,1250 \mathrm{Aa}$ & $5,6250 \mathrm{Aa}$ & $5,9166 \mathrm{~A}$ \\
Média TF & $8,3750 \mathrm{Aa}$ & $6,6875 \mathrm{Ab}$ & $3,0000 \mathrm{Bc}$ & $6,0208 \mathrm{~A}$ \\
Média do Dia & $7,1875 \mathrm{a}$ & $6,4062 \mathrm{a}$ & $4,3125 \mathrm{~b}$ & \\
\hline
\end{tabular}

Letras minúsculas diferentes na mesma linha indicam diferença. Letras maiúsculas diferentes na mesma coluna indicam diferença. Tratamento convencional (TC); terapia fotodinâmica (TF).

O tratamento da periodontite iniciou com a correção da causa primária, remoção do fio de algodão, que teve papel análogo à ampliação odontoclástica. Em seguida, efetuou-se a limpeza e o desbridamento, que, conforme Klugh (2005); Casey (2013) e Tremaine (2013), propiciam a cicatrização, pela remoção de bactérias e do tecido danificado. Esse tratamento (TC) foi empregado nos dois grupos, no dia zero, após o exame clínico.

Em alguns casos, uma terapia adjuvante é necessária, seja pela gravidade da lesão, seja pela patogenicidade dos agentes envolvidos (Klugh, 2005; Rawlinson e Earley, 2013; Tremaine, 2013). Por isso, há a indicação de antibióticos, sendo preferíveis locais, pelos efeitos adversos (Tremaine, 2013). A terapia fotodinâmica, segundo Alwaeli et al. (2015); Jervøe-Storm et al. (2015); Moreira et al. (2015); Queiroz et al. (2015); Carrera et al. (2016); Pulikkotil et al. (2016); Vohra et al. (2016) e Belinello-Souza et al. (2017), tem essa indicação, e, pela forma de ação, tem a vantagem de não causar resistência bacteriana (Jervøe-Storm et al., 2015; Vohra et al., 2016). Até a conclusão deste estudo, não havia estudos publicados da terapia fotodinâmica nessa afecção, em equinos.

O azul de metileno é um corante, da classe dos fenotiazínicos, que pode ser utilizado como fotossensibilizador (Carrera et al., 2016; Junqueira et al., 2016), o qual possui boa interação com a fonte de luz empregada neste estudo, LEDs, vermelho visível. O azul de metileno tem boa eficácia no combate de microrganismos (Jervøe-Storm et al., 2015; Carrera et al., 2016); seus monômeros têm o espectro de absorção em $664 \mathrm{~nm}$ e dímeros em $59 \mathrm{~nm}$, o que configura excelente absorção da luz pelos tecidos (Junqueira et al., 2016) e boa interação com a luz utilizada. Para essa absorção, pelas bactérias e tecidos danificados, houve a espera de um minuto, antes de incidir a luz de LEDs, como indicado por Ervolino et al. (2019).
Neste estudo, o emprego do azul de metileno ocorreu por meio de sol-gel, desenvolvido e testado in vitro por Junqueira et al. (2016), o que facilitou a aplicação pela seringabilidade e geleificação ao entrar em contato com a temperatura corporal, propiciando o preenchimento adequado da bolsa periodontal e aderência durante o período estipulado de incidência luminosa, 10 minutos. Assim, confirmaram-se in vivo as características testadas in vitro, sendo demonstrada praticidade, sem causar efeitos colaterais, por isso houve excelente aplicação em equinos.

$\mathrm{O}$ teste $\mathrm{F}$ (Tab. 4) apontou interações entre os grupos (TC e TF) e/ou entre os dias (zero, sete e 30). O desdobramento das interações por meio da análise das médias (Tab. 5), desconsiderando-se o grupo, apontou semelhanças entre os valores dos dias zero e sete, e o dia 30 como o menor, conferindo tendência à melhora, também evidenciada pelos autores Alwaeli et al. (2015); Campanile et al. (2015) e Moreira et al. (2015).

As profundidades dos sulcos gengivais, em função do tempo (dias zero, sete e 30), foram submetidas à análise de regressão polinomial, a qual demonstrou no TC que não houve modelo matemático ajustável $\left(\mathrm{R}^{2}=0,0405\right)$, constatando semelhança das profundidades no período estudado, parábola laranja (Fig. 3). Por outro lado, na TF, para avaliar a melhora clínica, por meio da profundidade do sulco gengival em função do tempo, notou-se ajuste significativo para $\mathrm{o}$ modelo linear $\left(\mathrm{R}^{2}=0,74\right)$, com queda média da profundidade de $20 \%$ do dia zero ao sete, e $64 \%$ do dia zero ao 30, parábola azul (Fig. 3). Os trabalhos de Moreira et al. (2015); Queiroz et al. (2015) e Pulikkotil et al. (2016) constataram também superioridade do grupo TF, mas diferentemente do presente estudo, obtiveram melhora nos dois grupos. 


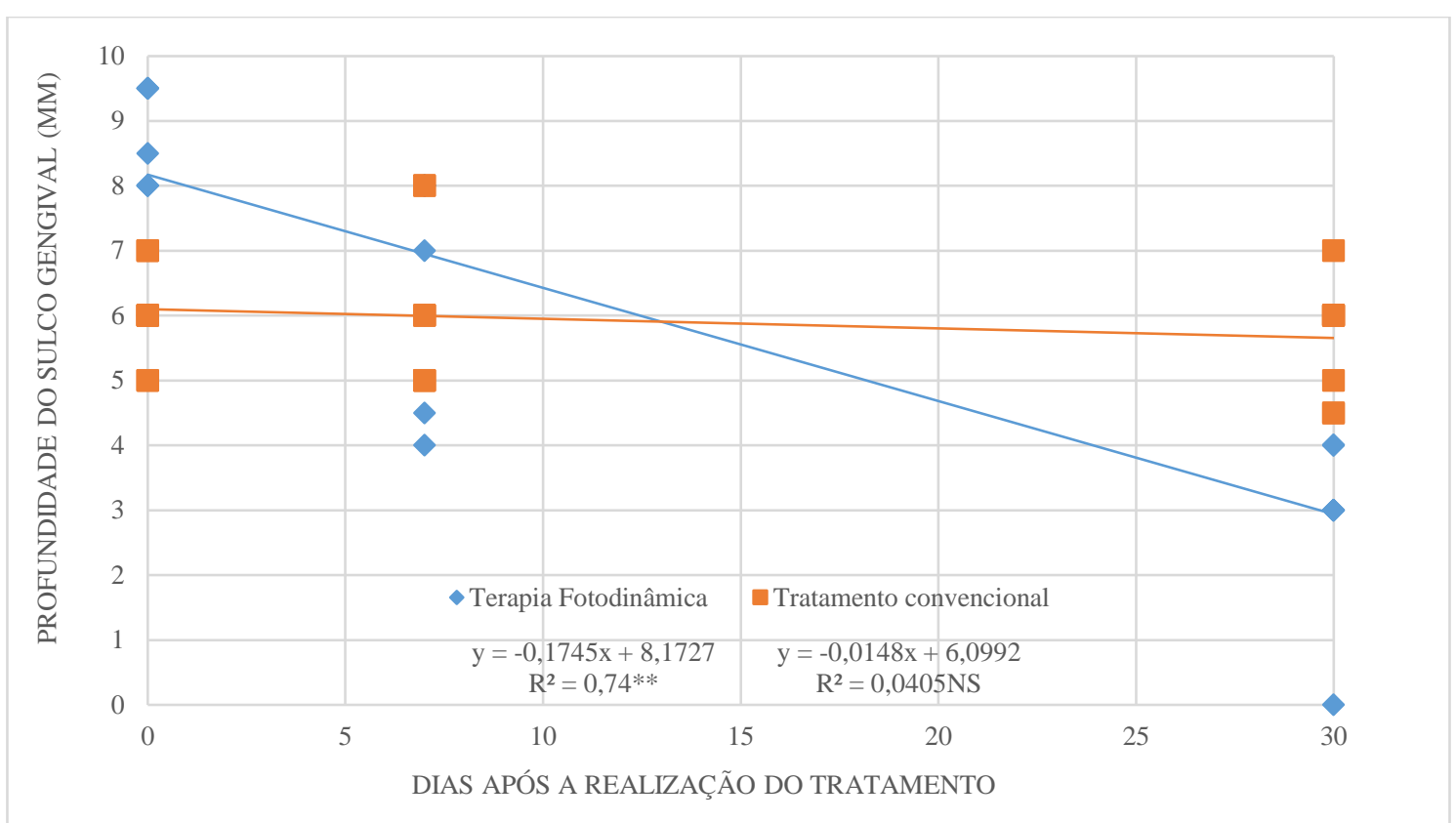

Figura 3. Profundidade dos sulcos gengivais dos equinos estudados, abscissa, no período de 30 dias, ordenada, dos dois grupos. Série 1) terapia fotodinâmica (azul). Série 2) tratamento convencional (laranja).

Conforme a Fig. 3, Tab. 2, 3, 4 e 5, no dia zero as lesões tinham o mesmo grau (dois) em todos os periodontos, mas houve diferença estatística quanto à profundidade, sendo o grupo TF superior (Fig. 3, Tab. 4 e 5). Mesmo com essa superioridade, a recuperação proporcionada pela TF foi mais rápida e efetiva, o que possibilitou, no dia sete, não haver mais diferença entre os grupos, ter sido deste grupo o único periodonto recuperado, e o dia 30 estar com valores inferiores estatisticamente (Fig. 3, Tab. 3 e 5), enquanto no grupo TC não houve melhora estatística nesse período. Os autores Alwaeli et al. (2015); Campanile et al. (2015) e Moreira et al. (2015) também observaram melhora destacada do grupo TF, e Belinello-Souza et al. (2017) identificaram melhora no grupo TF, com apenas sete dias de avaliação, destacando-se a superioridade da TF ao TC, mesmo em um curto período de avaliação. Por meio da comparação dos resultados, entre os dois grupos, desconsiderando-se os dias (Tab. $4 \mathrm{e}$ 5), foi observada semelhança entre os resultados, apesar das diferenças já discutidas. Isso ocorreu pelos altos valores, no dia zero, para o grupo TF, associado à pouca alteração entre os valores dos dias, no grupo TC.

Os resultados das interações (Tab. 4) com os desdobramentos (Tab. 5) permitiram avaliar cada grupo (Tab. 5). No grupo TF, confirmou-se o comportamento sugerido pela respectiva parábola, azul (Fig. 3), o qual apresentou o dia zero com a maior profundidade, recuperação já aos sete dias e destacada com 30, atingindo, pela média, o valor considerado saudável, de $3 \mathrm{~mm}$ (Tab. 2, 3 e 5). Embora o TC (parábola laranja) tenha tido uma profundidade menor no dia zero, em comparação ao TF, a melhora foi mais lenta e insignificante, em relação ao seu próprio eixo de profundidade. Tal característica foi confirmada pelo teste $\mathrm{t}$ de Student, pois não houve diferenças entre os dias (Tab. 5).

Essas constatações das interações e seus desdobramentos da análise fatorial complementam a observação do gráfico. Apesar de haver uma melhora numérica $(6,25 \%)$ em 30 dias para o grupo TC, não foi possível um modelo matemático ajustável para a regressão polinomial, com dados bem semelhantes tanto para zero quanto para sete e 30 dias, e também não houve diferença estatística entre esses dias pelo teste $t$ de Student. Como observaram Belinello-Souza et al. (2017), a melhora ocorreu apenas no grupo tratado com TF.

O período de avaliação após o tratamento, utilizado no presente estudo, foi eficaz para constatar a superioridade da TF em relação ao TC. As sete aplicações em 13 dias da TF se 
demonstraram eficazes, com melhora já aos sete dias de tratamento, destacada com $60 \%$ de resolução aos 30 dias, e com melhora evidente em todos os periodontos, enquanto o grupo TC teve uma pequena melhora da profundidade apenas aos 30 dias, não detectada estatisticamente, e em nenhum periodonto houve resolução. Nos seus estudos, Campanile et al. (2015) e Moreira et al. (2015) empregaram aplicações múltiplas da TF nessa afecção e também observaram superioridade em relação ao TC, em humanos.

A aplicação da TF adjuvante foi testada pela análise FOFA, Tab. 6, que ponderou as forças e fraquezas, constatadas neste estudo e em comparação a outros, bem como as oportunidades e ameaças em adotar essa técnica na rotina clínica.

Tabela 6. Análise das forças, oportunidades, fraquezas e ameaças (FOFA), considerando-se fatores internos e externos, positivos e negativos, da terapia fotodinâmica como tratamento da doença periodontal, na rotina odontológica equina

\begin{tabular}{|c|c|c|}
\hline & Fatores positivos & Fatores negativos \\
\hline \multirow[b]{2}{*}{$\begin{array}{l}\text { Fatores } \\
\text { internos }\end{array}$} & Forças & Fraquezas \\
\hline & $\begin{array}{l}\text { melhora dos resultados; } \\
\text { prevenção de perdas dentárias; } \\
\text { controle bacteriano; } \\
\text { resposta inflamatória; } \\
\text { ação local; } \\
\text { sem efeitos colaterais; } \\
\text { custo baixo; } \\
\text { fácil aplicação; } \\
\text { pouco tempo no sulco gengival. }\end{array}$ & $\begin{array}{l}\text { custo de aquisição; } \\
\text { concorrência (géis mucoadesivos). }\end{array}$ \\
\hline \multirow[b]{2}{*}{$\begin{array}{l}\text { Fatores } \\
\text { externos }\end{array}$} & Oportunidades & Ameaças \\
\hline & $\begin{array}{l}\text { preocupação com resistência bacteriana; } \\
\text { busca por tratamentos especializados; } \\
\text { demanda por tratamento odontológico (animal } \\
\text { ou equino); } \\
\text { boa casuística; } \\
\text { emprego em outras afecções (também de boa } \\
\text { ocorrência). }\end{array}$ & $\begin{array}{l}\text { crise financeira: } \\
\text { descontinuidade (aplicações } \\
\text { múltiplas); } \\
\text { preço maior; } \\
\text { desconhecimento (técnicos e leigos). }\end{array}$ \\
\hline
\end{tabular}

Ao se considerarem os fatores positivos da análise FOFA (Tab. 6), primeiramente, em se tratando das forças, a TF possui grande potencial para melhorar os resultados, como demonstrado neste trabalho e também destacaram Alwaeli et al. (2015); Campanile et al. (2015); Moreira et al. (2015) e Belinello-Souza et al. (2017). A TF evita perdas dentárias, proporciona controle bacteriano e melhora da resposta inflamatória (Moreira et al. 2015), com ação local segura, sem efeitos colaterais (Moreira et al., 2015; Ervolino et al., 2019) e resistência (Jervøe-Storm et al., 2015; Vohra et al., 2016), com custo baixo e fácil aplicação.

Não exige a permanência de compostos por longos períodos no sulco gengival, que causaria desconforto, e encerramento do protocolo, por perda ou desintegração precoce. Quanto às oportunidades, alternativas para o combate de afecções bacterianas, com segurança, têm aumentado, assim como a demanda por veterinários especialistas e o entendimento da necessidade da saúde oral em equinos. A periodontite é comum na clínica odontológica equina (Casey, 2013) e de diversos animais, e a TF adjuvante pode ser empregada também em outras afecções, como tumores cutâneos (sarcoides, carcinomas de células escamosas), neoplasias do trato urinário e gliomas (Dobson $e t$ al., 2018).

Os pontos negativos, Tab. 6, demonstraram fraquezas facilmente superadas pelos pontos positivos, como o custo de aquisição da fonte de luz, diluído pela boa casuística da periodontite (Casey, 2013) e por essa fonte ser indicada a outras enfermidades de ocorrências iguais ou 
superiores (Dobson et al., 2018), além de melhorar os resultados clínicos. Quanto às ameaças, algumas são facilmente superadas, como a concorrência, visto que os principais são géis mucoadesivos com antibióticos, também de ação local, com efeito colateral inferior aos antibióticos sistêmicos, mas com desenvolvimento de resistência bacteriana, bem como alta tolerância dos biofilmes à ação antisséptica e antimicrobiana (Jervøe-Storm et al., 2015) e a possibilidade de descontinuidade do tratamento por perdas ou desintegração precoce.

Já algumas ameaças exigem estratégias, como a crise financeira, que interfere na continuidade do tratamento quanto às aplicações múltiplas, podendo ser adotada apenas uma aplicação, por exemplo. Ou, ainda, o desconhecimento da técnica, a qual pode ser menosprezada por veterinários e tutores. Para adquirir esse conhecimento, são essenciais trabalhos científicos como este, que comprovam sua eficácia e relatam a forma de ação e aplicações, bem como ações de conscientização e divulgação quanto ao uso racional de antibióticos e da TF. Uma ameaça que não pode ser solucionada com características próprias é o proprietário evitar protocolo que eleve, mesmo que insignificantemente, o preço. Apesar disso, os pontos positivos são mais preponderantes que os negativos.

\section{CONCLUSÃO}

O tratamento convencional (TC) não teve relação estatística com a melhora clínica da doença periodontal, em 30 dias pós-tratamento, enquanto a terapia fotodinâmica adjuvante (TF) demonstrou ser eficiente, com recuperação já aos sete dias, melhora significativa de todos os periodontos, com resolução completa em $60 \%$ e atingindo, pela média do grupo, a profundidade de periodonto saudável. A TF tem potencial para ser aplicada na rotina clínica, principalmente por melhorar os resultados clínicos, com segurança e facilidade de aplicação.

\section{REFERÊNCIAS}

ALWAELI, H.A.; AL-KHATEEB, S.N.; ALSADI, A. Long-term clinical effect of adjunctive antimicrobial photodynamic therapy in periodontal treatment: a randomized clinical trial. Lasers Med. Sci., v.30, p.801-807, 2015.
BELINELLO-SOUZA, E.L.; ALVARENGA, L.H.; LIMA-LEAL, C. et al. Antimicrobial photodynamic therapy combined to periodontal treatment: Experimental model. Photodiagnosis Photodyn. Ther., v.18, p.275-278, 2017.

CAMPANILE, V.S.M.; GIANNOPOULOU, C.; CAMPANILE, G. et al. Single or repeated antimicrobial photodynamic therapy as adjunct to ultrasonic debridement in residual periodontal pockets: clinical, microbiological, and local biological effects. Lasers Med. Sci., v.30, p.27-34, 2015.

CARRERA, E.T.; DIAS, H.B.; CORBI, S.C.T. et al. The application of antimicrobial photodynamic therapy (aPDT) in dentistry: a critical review. Laser Phys., v.26, p.123001, 2016.

CASEY, M. A new understanding of oral and dental pathology of the equine cheek teeth. Vet. Clin. N. Am. Equine Pract., v.29, p.301-324, 2013.

DOBSON, J.; QUEIROZ, G.F.; GOLDING, J.P. Photodynamic therapy and diagnosis: Principles and comparative aspects. Vet. J., v.233, p.8-18, 2018.

ERVOLINO, E.; STATKIEVICZ, C.; TORO, L.F. et al. Antimicrobial photodynamic therapy improves the alveolar repair process and prevents the occurrence of osteonecrosis of the jaws after tooth extraction in senile rats treated with zoledronate. Bone, v.120, p.101-113, 2019.

GRIFFIN, C. The gold standard of dental care: the juvenile horse. Vet. Clin. N. Am. Equine Pract., v.29, p.487-504, 2013.

JERVØE-STORM, P.M.; JEPSEN, S.; WORTHINGTON, H.V. et al. Adjunctive antimicrobial photodynamic therapy for treating periodontal and peri-implant diseases. Cochrane Database Syst. Rev., n.6, 2015.

JUNQUEIRA, M.V.; BORGHI-PANGONI, F.B.; FERREIRA, S.B. et al. Functional polymeric systems as delivery vehicles for methylene blue in photodynamic therapy. Langmuir, v.32, p.19-27, 2016.

KENNEDY, R.S.; DIXON, P.M. The aetiopathogenesis of equine periodontal diseasea fresh perspective. Equine Vet. Educ., v.30, p.161-168, 2018. 
KLUGH, D.O. Equine periodontal disease. Clin. Techn. Equine Pract., v.4, p.135-147, 2005.

MOREIRA, A.L.; NOVAES JR, A.B.; GRISI, M.F. et al. Antimicrobial photodynamic therapy as an adjunct to non-surgical treatment of aggressive periodontitis: a split-mouth randomized controlled trial. J. Periodontol., v.86, p.376-386, 2015.

PULIKKOTIL, S.J.; TOH, C.G.; MOHANDAS, K.; LEONG, K.V.G. Effect of photodynamic therapy adjunct to scaling and root planing in periodontitis patients: a randomized clinical trial. Aus. Dental J., v.61, p.440-445, 2016.

QUEIROZ, A.C.; SUAID, F.A.; ANDRADE, P.F. et al. Adjunctive effect of antimicrobial photodynamic therapy to nonsurgical periodontal treatment in smokers: a randomized clinical trial. Lasers Med. Sci., v.30, p.617-625, 2015.
RAWLINSON, J.T.; EARLEY, E. Advances in the treatment of diseased equine incisor and canine teeth. Vet. Clin. N. Am. Equine Pract., v.29, p.411-440, 2013.

TREMAINE, H. Advances in the treatment of diseased equine cheek teeth. Vet. Clin. N. Am. Equine Pract., v.29, p.441-465, 2013.

VOHRA, F.; AKRAM, Z.; SAFII, S.H. et al. Role of antimicrobial photodynamic therapy in the treatment of aggressive periodontitis: a systematic review. Photodiagnosis Photodyn. Ther., v.13, p.139-147, 2016. 